\title{
32-CHANNEL DWDM SYSTEM WITH DIFFERENT AMPLIFIERS AND MODULATIONS
}

\author{
Norbert ZDRAVECKÝ, L'uboš OVSENÍK, Jakub ORAVEC, Maroš LAPČÁK \\ Department of Electronics and Multimedia Telecommunication, Faculty of Electrical Engineering and Informatics, \\ Technical University of Košice, Letná 9, 04200 Košice, Slovak Republic, \\ Tel. +421 55602 4277, E-mail: norbert.zdravecky@tuke.sk
}

\begin{abstract}
Wavelength Division Multiplexing is a technology that has enabled the transmission of huge amounts of data at high transfer rates over a single optical fiber. The capacity of an optical channel is usually affected by the shape of signal, nonlinear characteristics and dispersion. In this article, we focus on the DWDM system, optical amplifiers, and optical modulations in 32-channel DWDM system, which was designed in the OptiSystem program. We evaluate the parameters BER (Bit Error Rate) and Q factor for $40 \mathrm{~Gb} / \mathrm{s}$ systems with changing amplifiers.
\end{abstract}

Keywords: DWDM, DPSK, EDFA, optical amplifiers, optical modulations, ROA

\section{INTRODUCTION}

With the advent of Wavelength Division Multiplexing (WDM) and Dense WDM (DWDM), the Optical Transmission Network (OTN) has been standardized by the International Telecommunication Union (ITU-T) as the core network infrastructure. Optical communication systems with 40 to 80 channels which used transmission speed of $10 \mathrm{~Gb} / \mathrm{s}$ no longer meet the requirements for modern transmission systems. Bandwidth can be increased by installing more optical cables, increasing the bit rate of the system, or multiplexing different wavelengths (WDM). A key breakthrough in the field of optical communication networks occurred in the late 1990s and the beginning of the new millennium. The improvement was proposal of the second generation of WDM (narrowband WDM), in which 8 channels were used. The channels were separated by an interval of about $400 \mathrm{GHz}$ in the third window $(1550 \mathrm{~nm})$. Second reason was the first deployment of a completely new DWDM system. DWDM systems have also found application in transoceanic optical networks. The new generation optical communication systems will operate at a transmission speed of $40-112 \mathrm{~Gb} / \mathrm{s}$. The demand for multimedia is growing exponentially, so DWDM systems need to be adapted to meet these demands. To maximize the potential of DWDM networks, it is necessary to analyse the properties of the transmission medium and optimize all system parameters. In this work we will compare different designs of optical amplifiers and different designs of optical modulations and their influence on transmission limitation in DWDM systems [1][2].

\section{THEORETICAL APPROACH TO THE ISSUE}

In this chapter, we describe a general theory about the DWDM system, used modulations and amplifiers in our design.

\subsection{DWDM system}

DWDM systems are becoming more and more popular nowadays, but there are also limitations that the provider of these services must consider and deal with them. The main limitations in DWDM are limited transmission speed, limited capacity and maximum power, lasers and their use in DWDM system, relatively high production costs. From a technical and economic point of view, the ability to provide potentially unlimited transmission capacity is the most obvious advantage of DWDM technology. Current investments in optic structure can not only be maintained, but also optimized at least 32 times. In the event of a change in transmission network requirements, capacity can be increased by simply upgrading the equipment or increasing the number of wavelengths transmitted over the fibers without costly changes. The capacity of the channel can be obtained at the cost of equipping an existing optical fibers. DWDM systems with 32 channels can transmit a total bandwidth of $400 \mathrm{~Gb} / \mathrm{s}$ over a single fiber. It is estimated that more than 10.000 volumes of the encyclopedia can be transmitted per second. The number of channels also depends on the type of fibers. A single mode fibers can transmit about $80 \mathrm{~km}$ without amplification. Although DWDM technology is still evolving and technologists and standards bodies are addressing many issues, systems are already available with several dozen wavelengths in the same fiber. Soon we will see DWDM systems with several hundred wavelengths in one fiber. Theoretically, more than 1000 channels can be multiplexed in a thread [3]. Fig. 1 shows scheme of DWDM system.

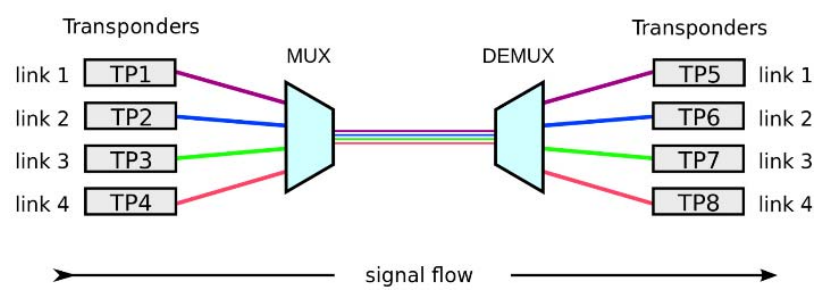

Fig. 1 Scheme of DWDM principle. 


\subsection{Optical modulations}

The importance of modulation lies in influencing the carrier optical signal by the information-carrying signal so that the resulting modulated signal can transmit the information over the greatest possible distance at the highest possible speed and at the lowest possible cost. Modulation can be performed either directly or indirectly using modulators separate from the lasers. Direct modulation is suitable for semiconductor lasers and is realized by modulation of the injected current [7]. Dielectric and gas lasers are usually modulated indirectly, using external modulators. Advanced modulations, which have caused a big leap in modern communications, have come to the fore mainly due to significantly improving utilization and capacity of the channel. Another significant plus is their improved performance in long-distance fiber optic communication. Especially due to the significantly improving properties over long distances, these technologies have started to be used and are often sought after [1][2]. In optical communication, a Mach-Zehnder interferometer is used, for example, as a demodulator of DPSK and DQPSK. Differential Phase Shift Keying (DPSK) is a fast and stable modulation format and is used as a tool for many optical applications. The main advantage is lower error rate compared to simple modulations and it is not necessary to know the whole absolute phase. DPSK is a type of phase modulation that changes the phase of the carrier wave [5][6]. The principle of modulation is a phase rotation of 180 degrees occurring for the logical unit. For logical zero, the phase does not rotate, it remains the same as for the previous one symbol. The main advantage of DPSK is the intensity improvement of $3 \mathrm{~dB}$, which means better sensitivity of the receiver compared to OOK (on-off keying) modulation [8].

Differential Quadrature Phase Shift Keying (DQPSK) has gained popularity due to its ability to transmit long signals. In addition, it is less prone to noise when passing through several narrow channels in wavelength division multiplexing (DWDM) [4][5]. In the case of DQPSK modulation, the bit pairs correspond to the given phase shifts (not specific phase values). A phase shift from the initial phase is given or we can consider a $90^{\circ}$ phase shift between adjacent symbols.

\subsection{Optical amplifiers}

In an optical amplifier, the input signal is modulated to a wavelength that the optical conductor is able to transmit optimally. Due to the unequal amount of attenuation for different wavelengths, wavelengths which provide minimal attenuation are used. These are mainly values around $850 \mathrm{~nm}, 1310 \mathrm{~nm}$ (S band) and $1550 \mathrm{~nm}$ (C band). The area around $850 \mathrm{~nm}$ is very narrow and still has a relatively large attenuation. The EDFA (Erbium-Doped Fiber Amplifier) are devices that have been developed over two decades and function as elements of concentrated optical gain in terrestrial, submarine and access networks [12]. The erbium doped fiber amplifier can operate reliably at high data rates in a multi-wavelength environment, because of its slow gain dynamics. Raman Optical Amplifiers (ROA) have made it possible to significantly increase efficiency and increase performance. ROAs are not effective at a particular wavelength band. Like the Semiconductor Optical Amplifier (SOA), optical amplifiers are designed for signal regeneration and can be classified according to the tasks they play in optical networks. The terminal amplifier element, referred to as the preamplifier, is used to amplify the weak channel before its conversion from the photonic to the electronic domain (Fig. 2). This type provides high gain $(>30 \mathrm{~dB})$, works with a small signal input $\left(\mathrm{P}_{\mathrm{in}}<25 \mathrm{dBm}\right)$ and delivers minimal excessive noise [13]. Repeated optical transmission relies on in-line amplifiers designed to regenerate the signal after each fiber span. The in-line amplifier must match the loss induced in the range and the loss of the in-line elements, normally providing gains greater than $20 \mathrm{~dB}$ [9]. Unlike a single-channel preamplifier, an in-line amplifier is designed and operated as a multichannel amplification block in wavelength and multiplex (WDM) links. At the beginning of the transmission in the WDM system, an amplifier (or power amplifier), which triggers the increased power of the channel and maintains the integrated signal deep into the light connection [1][2].

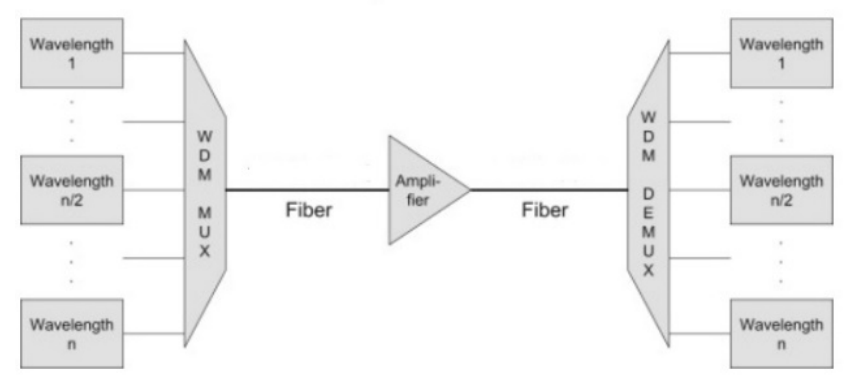

Fig. 2 Amplified transmission of light waves in WDM

\section{DESIGN OF 32- CHANNEL ULTRA-DWDM SYSTEM WITH DIFFERENT AMPLIFIERS}

The first design consists of lasers (power $0 \mathrm{dBm}$ ), modulators, a multiplexer and a demultiplexer, an optical fiber, a dispersion compensating optical fiber (DCF), EDFA amplifiers (ROA amplifier) and optical receivers [10]. The parameters of the 32 channels DWDM of the proposed model are the transmission speed of $40 \mathrm{~Gb} / \mathrm{s}$, the central frequency is $193.1 \mathrm{THz}$, the frequency spacings are $100 \mathrm{GHz}$. The total optical distance is $60 \mathrm{~km}$. In the scheme we created a transmitter part (Fig. 3), channel part (Fig. 4) and receiver part (Fig. 5). 


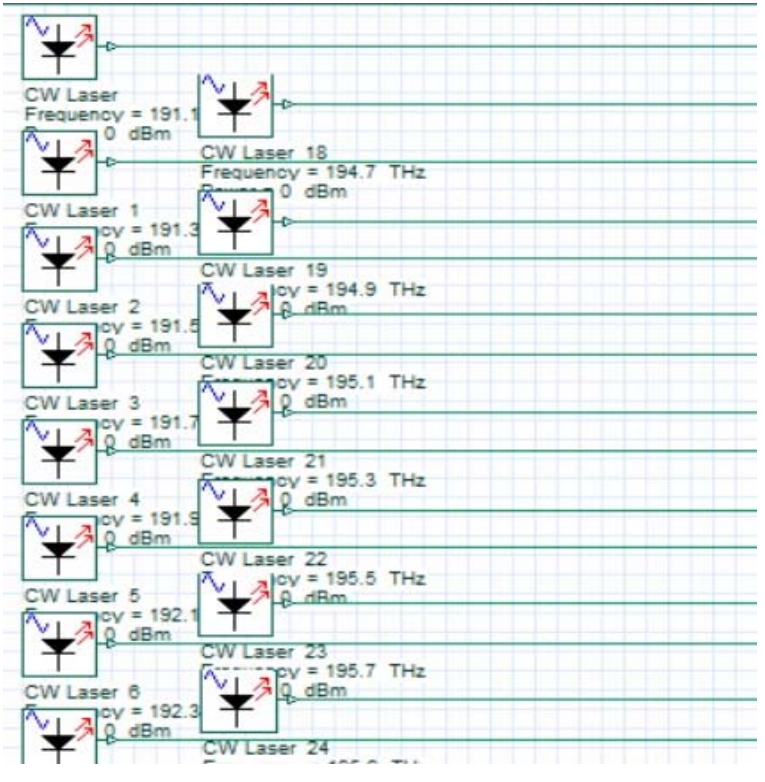

Fig. 3 Transmitter part of schematics of DWDM

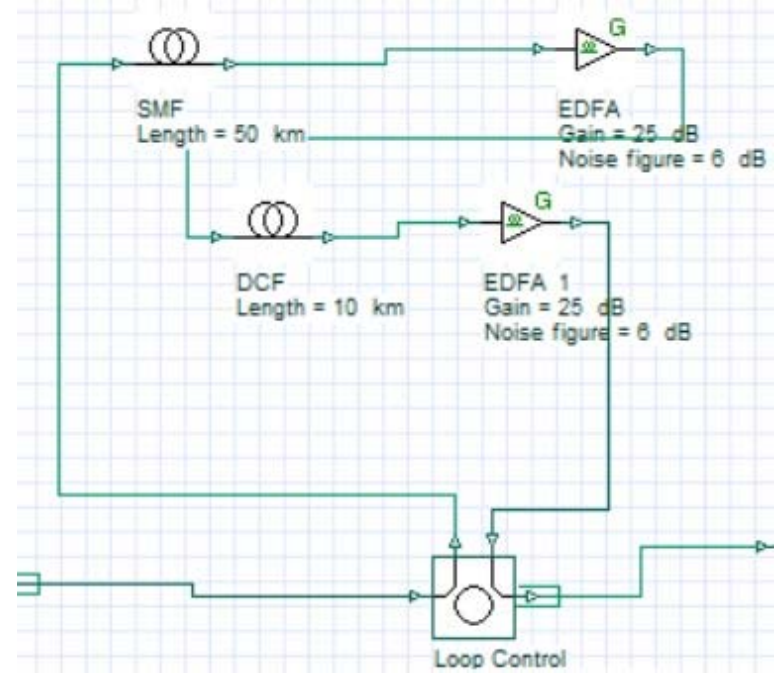

Fig. 4 Channel part of schematics of DWDM

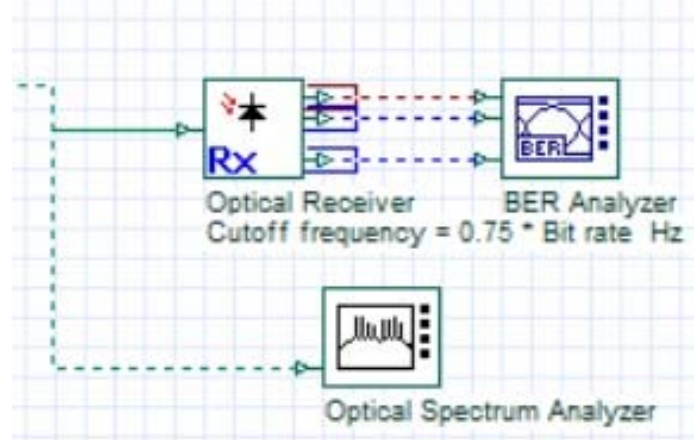

Fig. 5 Receiver part of schematics of DWDM

Results of 32 channel DWDM (EDFA) system shown as eye diagram on Fig. 6 . The BER value is calculated from eye diagrams. BER for first channel $3.22 \times 10^{-63}$. Fig. $6 \mathrm{~A}$ shows eye diagram of channel one and Fig. $6 \boldsymbol{B}$ shows eye diagram of channel ten.

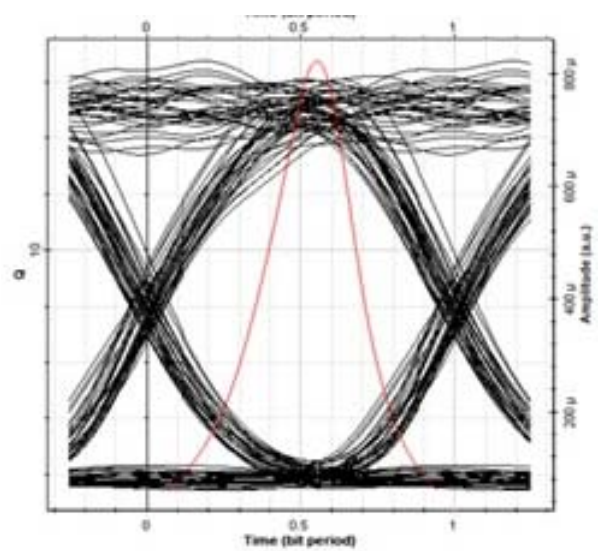

Fig. 6 A Eye diagram of first channel (DWDM - EDFA)

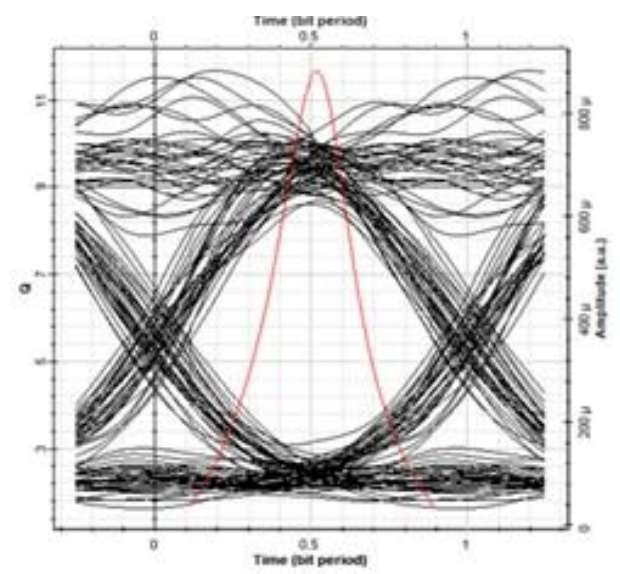

Fig. 6 B Eye diagram of tenth channel (DWDM - EDFA)

In our diagram, we changed the amplifier (ROA) in the channel part of scheme (Fig. 7).

Results of DWDM (ROA) system with 32 channels is shown on Fig. 8. Fig. $8 \mathrm{~A}$ shows eye diagram of channel one and Fig. $8 \boldsymbol{B}$ shows eye diagram of channel ten in this scheme.

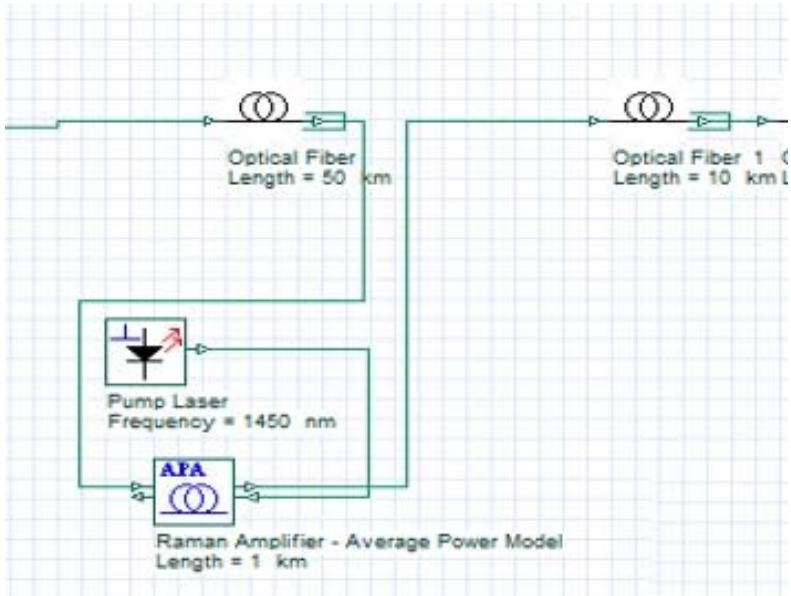

Fig. 7 Channel part of DWDM system with ROA amplifier 


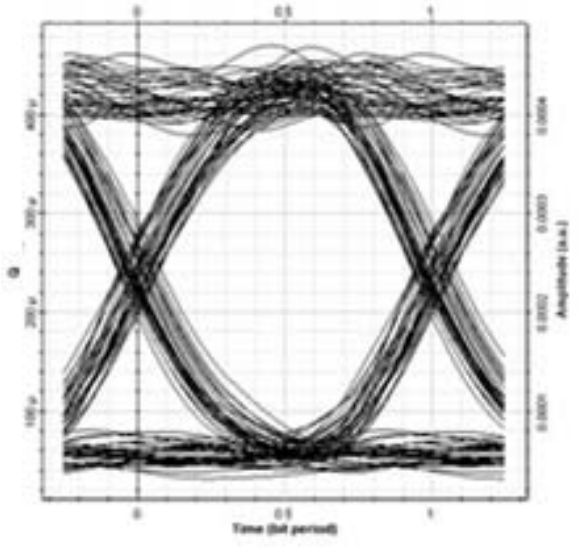

Fig. 8 A Eye diagram of first channel (DWDM -ROA).

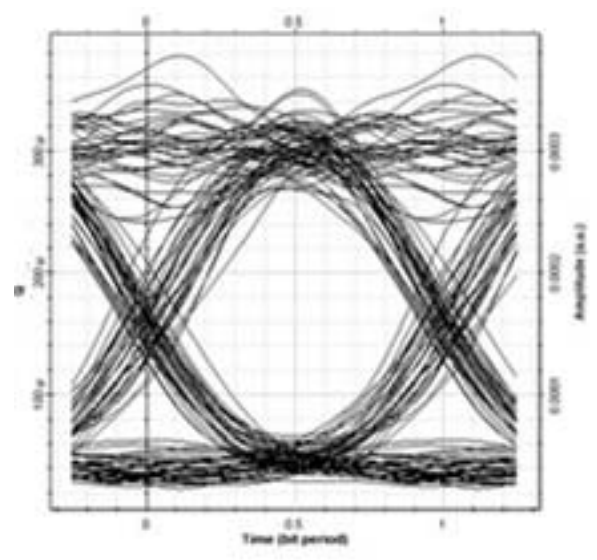

Fig. 8 B Eye diagram of tenth channel (DWDM -ROA)

The Table 1 shows BER, Q factor for channel one and channel ten in 32 channels DWDM. Zulherman et al. researched EDFA and ROA in Nonlinear-CWDM System with $10 \mathrm{~Gb} / \mathrm{s}$ bit rate, $60 \mathrm{~km}$ fiber length and $20 \mathrm{~nm}$ channel spacing. As a result, for a power of $0 \mathrm{dBm}$, the BER of DWDM system (ROA) was $5.646 \times 10^{-43}$ and for DWDM (EDFA) $2.110 \times 10^{-12}$. Q factor was DWDM (ROA) 14.863 and DWDM (EDFA) 9.426 [11].

Table 1 Resulting BER and Q factor values in DWDM with different amplifier

\begin{tabular}{|c|c|}
\hline \multicolumn{2}{|c|}{ DWDM (EDFA) channel 1} \\
\hline Frequency & $193.1 \mathrm{GHz}$ \\
\hline BER & $3.22 \times 10^{-63}$ \\
\hline Q factor & 16.7374 \\
\hline \multicolumn{2}{|c|}{ DWDM (EDFA) channel 10} \\
\hline Frequency & $194 \mathrm{GHz}$ \\
\hline BER & $8.86 \times 10^{-32}$ \\
\hline Q factor & 11.6693 \\
\hline
\end{tabular}

\begin{tabular}{|c|c|}
\hline \multicolumn{2}{|c|}{ DWDM (ROA) channel 1} \\
\hline Frequency & $193.1 \mathrm{GHz}$ \\
\hline BER & $2.59 \times 10^{-50}$ \\
\hline Q factor & 14.8679 \\
\hline \multicolumn{2}{|c|}{ DWDM (ROA) channel 10} \\
\hline Frequency & 194 \\
\hline BER & $5.51 \times 10^{-25}$ \\
\hline Q factor & 10.2499 \\
\hline
\end{tabular}

\section{DESIGN OF 32- CHANNEL ULTRA-DWDM SYSTEM WITH DIFFERENT MODULATIONS}

The second design consists of lasers, modulators, a multiplexer and a demultiplexer, an optical fiber, a dispersion compensating optical fiber (DCF), EDFA amplifiers (ROA amplifier) and optical receivers. The parameters of the 32 channels DWDM of the proposed model are the transmission speed of $40 \mathrm{~Gb} / \mathrm{s}$, the central frequency is $193.1 \mathrm{THz}$, the frequency spacings are $100 \mathrm{GHz}$. The total optical distance is $60 \mathrm{~km}$. Fig. 9 and Fig. 10 show OptiSystem schemes of used modulations.

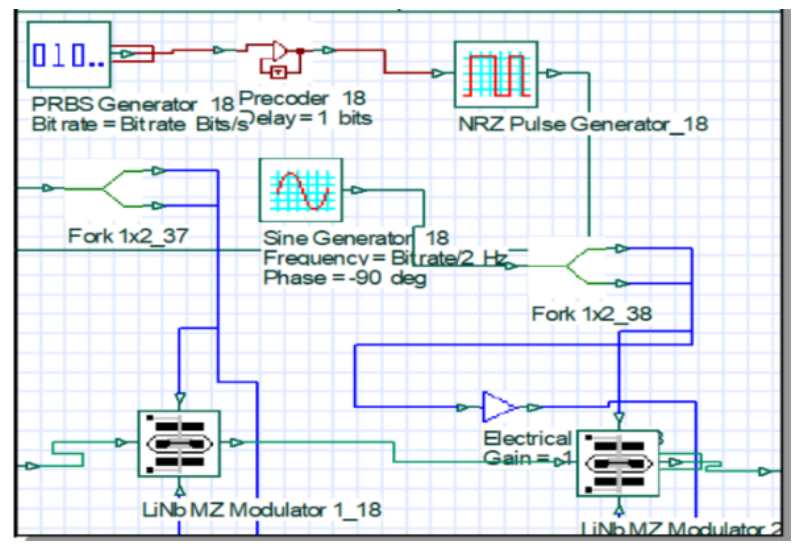

Fig. 9 Scheme of DPSK modulation

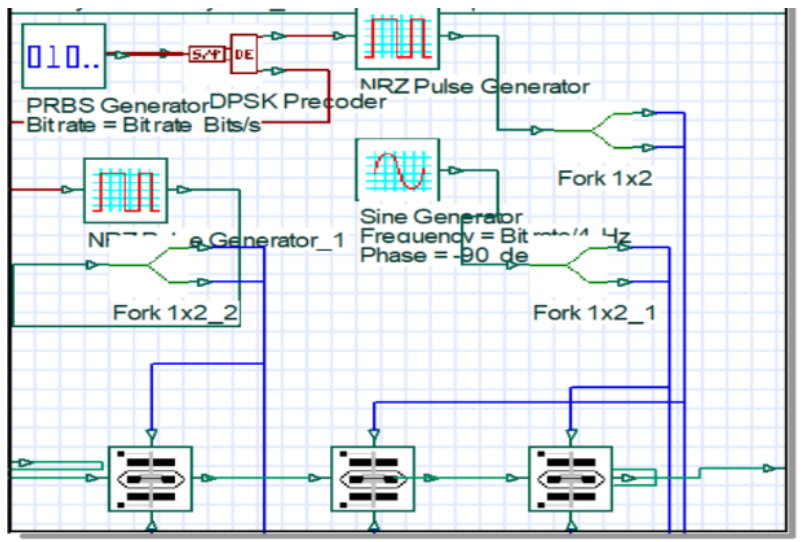

Fig. 10 Scheme of DQPSK modulation 
Results of 32 channels DWDM system with DPSK modulation is shown in Fig. 11.

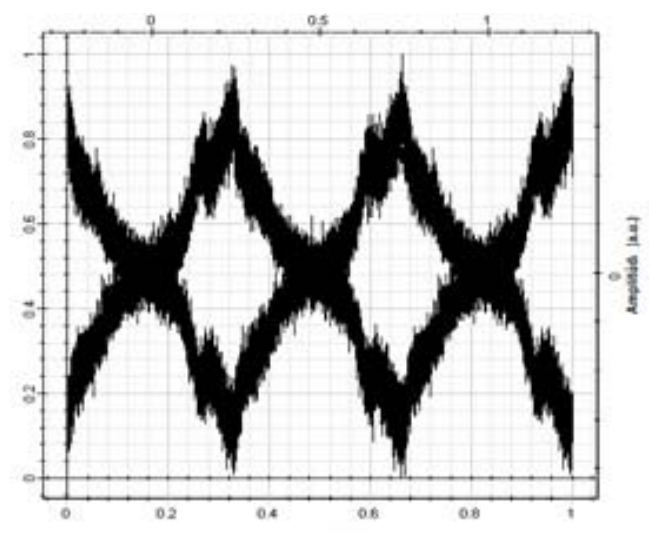

Fig. 11 Eye diagram of $40 \mathrm{~Gb} / \mathrm{s}$ DWDM (DPSK)

Eye diagram as a result of 32 channels DWDM system with DQPSK modulation is shown in Fig. 12.

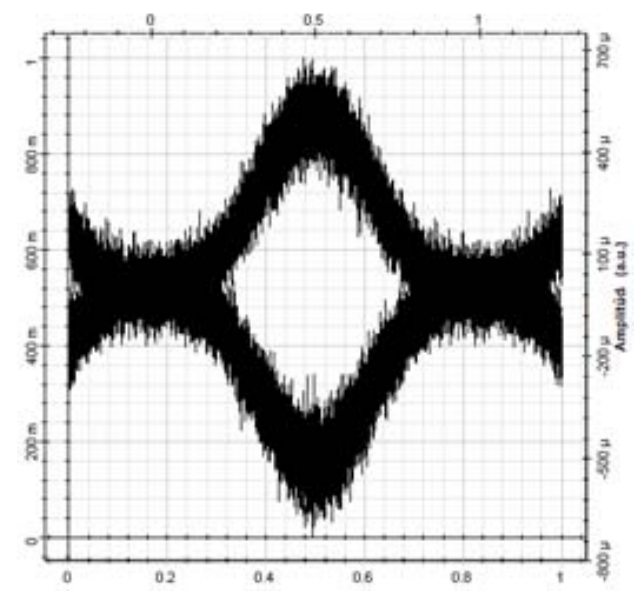

Fig. 12 Eye diagram of $40 \mathrm{~Gb} / \mathrm{s}$ DWDM (DQPSK)

Table 2 shows eye height, BER, Q factor for our $40 \mathrm{~Gb} / \mathrm{s} 32$ channel DWDM scheme.

Table 2 Resulting BER and Q factor values in DWDM with different modulations

\begin{tabular}{lc}
\hline \multicolumn{2}{c}{ DWDM (DPSK) } \\
\hline Eye height & 0.0009 \\
\hline BER & $6.19 \times 10^{-25}$ \\
\hline Q factor & 10.2448 \\
\hline \multicolumn{2}{c}{ DWDM (DQPSK) } \\
\hline Eye height & 0.0007 \\
\hline BER & $1.83698 \times 10^{-24}$ \\
\hline Q factor & 10.1398 \\
\hline
\end{tabular}

\section{CONCLUSIONS}

Changing important parameters such as path length, baud rate, laser gain, frequency change can have a positive or negative effect on the received signal for modulation. In this work we describe situations with different amplifiers and different modulations in a 32 channels DWDM system. By simulating a communication system using an EDFA and ROA amplifier, we found from the measured values that the values of the Q factor and BER are well above the threshold values. In the eye diagram, the intersymbol interference in signal transmission over the length of the optical network was $60 \mathrm{~km}$ at a transmission speed of $40 \mathrm{~Gb} / \mathrm{s}$. As the baud rate increased, the signal transmission quality deteriorated. Multistate modulations (with more than two states), for example DPSK, DQPSK, combine phase and amplitude modulation or phase and polarization. These modulations appear to be promising for high-speed and long-distance transmission systems Nonlinear phenomena were not included in the simulation, so some results may have been excessively better. The aim was to compare amplifiers and modulations with each other.

\section{ACKNOWLEDGMENTS}

This work was supported by research projects VEGA $1 / 0584 / 20$ "UWB sensor systems for monitoring people working in real conditions (ReConLoc)" and FEEI-202171 "Methods of data security in modern communication systems".

\section{REFERENCES}

[1] MUKHERJEE, B. - TOMKOS, I. - WINZER, P. ZHAO, Y.: Handbook of Optical Networks. Switzerland. Gewerbestrasse 11, 6330 Cham, 2020, ISBN: 978-3-030-16250-4, 1169 pp.

[2] AGRAWAL, G. P.: Fiber-Optic Communication Systems (Third Edition). New York: The Institute of Optics University of Rochester, 2002, ISBN: 0-47122114-7, 546 pp.

[3] HUSZANIK, T. - TURÁN, J. - OVSENÍK, L.: On the Impact of Fiber Nonlinear Effects on the CPDQPSK Modulated Ultra-DWDM System. Acta Electrotechnica et Informatica. 2019, 19(4), 21-28. ISSN 1335-8243. Available on: DOI: 10.15546/aeei2019-0026

[4] WINZER, P. J.: Energy-Efficient Optical Transport Capacity Scaling Through Spatial Multiplexing. IEEE Photonics Technology Letters. 2011, 23(13), 851 - 853. ISSN 1041-1135. Available on.: DOI: 10.1109/ LPT.2011.2140103

[5] BOSCO G. - CARENA, A. - MEMBER, IEEE CURRI, V. - GAUDINO, R. - POGGIOLINI, P.: On the Use of NRZ, RZ, and CSRZ Modulation at 40 Gb/s With Narrow DWDM Channel Spacing, IEEE Journal of Lightwave Technology, Vol. 20, No. 9, Pages 1694-1704, 2002. 
[6] G.694.1: Spectral grids for WDM applications: DWDM frequency grid. ITU-T, 2020. Available on: https://www.itu.int/rec/T-REC-G.694.1/en

[7] LAUDE, J. P.: DWDM Fundamentals, Components, and Applications: Artech House Optoelectronics Library. London. Artech House, 2002. ISBN 9781580531771 .

[8] HUI, R.: Introduction to Fiber-Optic Communications. Cambridge, Massachusetts, USA. Academic Press, 2020. ISBN 978-0-12-805345-4.

[9] ZYSKIND, J. - SRIVASTAVA, A.: Optically amplified WDM networks. Amsterdam. Academic Press, 2011. ISBN 1282954474.

[10] HUSZANIK, T. - TURÁN, J. - OVSENÍK, L.: Utilization of 10 Gbps DWDM System with Duobinary Modulation into Passive Optical Network, Journal of Communications Software and Systems, vol. 14, no. 4, 2018, pp. 367 - 385. DOI: http://dx.doi.org/10.24138/jcomss.v14i4.644.

[11] ZULHERMAN, D. - FAHMI, F. - UTAMI, S. SANTOSO, T. H. - NUGROHO, S. A.: Comparative Analysis of Erbium Doped Fiber Amplifier (EDFA) and Raman Optical Amplifier (ROA) in NonlinearCWDM System. Jurnal Infotel. 2018, 10(3), 144-149. Available on: DOI: 10.20895/infotelv10i3.378

[12] HUSZANIK, T. - TURÁN, J. - OVSENÍK, L.: Vplyv konfigurácie čerpacieho zdroja EDFA na generovanie SPM vo WDM systémoch. Electrical Engineering and Informatics. 2019, (10), 42-47. ISBN 978-80-553-3342-7.

[13] HUSZANIK, T. - TURÁN, J. - OVSENÍK, L.: Utilization of 10 Gbps DWDM System with Duobinary Modulation into Passive Optical Network.
Journal of Communications Software and Systems. 2018, 14(4), 367-375. ISSN 1845-6421.

Received July 7, 2021, accepted September 17, 2021

\section{BIOGRAPHIES}

Norbert Zdravecký received his M.Sc. degree from Faculty of Electrical Engineering and Informatics, Technical University of Košice in 2020 and now he continues as PhD student. His research interests include data transmission limitation in all optical networks, optic communication systems

Maroš Lapčák received his M.Sc. degree from Faculty of Electrical Engineering and Informatics, Technical University of Košice in 2020 and now he continues as PhD student. His research interests include the study of data transmission limitations in FSO systems, the design of a hybrid FSO/RF system, the design of a backup RF line, hard and soft switching methods, and the recording of weather conditions in the atmosphere.

Luboš Ovseník received his M.Sc. and PhD. degrees from Faculty of Electrical Engineering and Informatics, Technical University of Košice in 1990 and 2002, respectively. He works at the Technical University of Košice, now as an Associate Professor. His research interests include photonics, fiber optic communication systems and sensor networks.

Jakub Oravec received his M.Sc. and PhD. degrees from Faculty of Electrical Engineering and Informatics, Technical University of Košice in 2015 and 2019, respectively. Nowadays, he serves as an Assistant Professor, his research interests include image encryption algorithms, steganography and digital image processing. 